\title{
Numerical Investigation of the Characteristics of the Dynamic Load Allowance in a Concrete-Filled Steel Tube Arch Bridge Subjected to Moving Vehicles
}

\author{
Qingfei Gao ${ }^{D},{ }^{1}$ Qilu Ma, ${ }^{1}$ Kemeng Cui, ${ }^{2}$ Jun $\mathrm{Li}^{3}{ }^{3}$ and Chuang $\mathrm{Xu}^{4}$ \\ ${ }^{1}$ School of Transportation Science and Engineering, Harbin Institute of Technology, Harbin 150090, China \\ ${ }^{2}$ School of Civil Engineering, Southeast University, Nanjing 210096, China \\ ${ }^{3}$ Department of Municipal and Environmental Engineering, Heilongjiang Institute of Construction Technology, Harbin, \\ Heilongjiang 150025, China \\ ${ }^{4}$ Heilongjiang Province Highway Survey and Design Institute, Harbin, Heilongjiang 150080, China \\ Correspondence should be addressed to Qingfei Gao; gaoqingfei@hit.edu.cn
}

Received 7 August 2020; Revised 1 September 2020; Accepted 3 September 2020; Published 17 September 2020

Academic Editor: Min Luo

Copyright (C) 2020 Qingfei Gao et al. This is an open access article distributed under the Creative Commons Attribution License, which permits unrestricted use, distribution, and reproduction in any medium, provided the original work is properly cited.

\begin{abstract}
Dynamic load allowance (DLA) is a key factor for evaluating the structural condition of bridges; however, insufficient research has been performed regarding the characteristics of DLA in concrete-filled steel tube (CFST) arch bridges. To address this issue, based on an actual CFST arch bridge, the DLA characteristics of bridges are investigated numerically in this study. First, aiming at different structural components, such as the arch rib, main girder, and suspenders, the DLA values obtained at various locations of different structural components are compared in detail, and then the changing regulations of the DLA, considering the influence of different vehicle speeds and various extents of pavement roughness, are summarized and analyzed. Additionally, the relationship between the different DLAs obtained by using the different response indices, that is, displacement, bending moment, and axis force of structure, is investigated. Finally, some conclusions that are significantly beneficial for evaluating or detecting the condition of CFST arch bridges are drawn.
\end{abstract}

\section{Introduction}

The concrete-filled steel tube (CFST) arch bridge, with its beautiful shape as a landmark building, has been favored by many engineers worldwide. In the CFST structure, the compressive strength of concrete is significantly improved due to the restraint of the steel tube while the stability of the steel tube is improved due to the concrete filling. The mechanical properties of the CFST structure have great advantages. In recent years, plenty of CFST arch bridges have been constructed worldwide, among which hundreds of CFST arch bridges have been built in China during the past 20 years [1].

The bridge structure bears a variety of loads, the most important of which is the moving vehicle loads. An understanding of the complex interaction between vehicle and bridge vibrations involves nonlinear and dynamic analyses, which have always been a concern in the engineering field. According to numerical analyses, some formulas for dynamic load allowance (DLA) have been suggested for CFST arch bridges [2, 3]. The dynamic responses and riding comfort of CFST arch bridges subjected to moving vehicles have been determined by finite element analysis and field tests [4-7]. In addition, the fatigue performance studies of steel-concrete composite bridges under vehicles have also been carried out [8].

The dynamic performance of bridge structures under vehicle loads is an important issue in bridge design and operating state assessment, which has attracted the attention of researchers and engineers. The DLA is the regular parameter to express the impact effect of moving vehicles. In recent years, many useful conclusions have been obtained on 
the coupling vibration of different bridge types, such as metro train-bridge, short-span slab bridge, composite steel bridge, and so forth [9-13]. The DLA is the most important factor in the dynamic performance of bridges due to moving vehicles. Therefore, the development of the vehicle-bridge coupled vibration and DLA has been summarized by many researchers at different times, which is very meaningful for other researchers [14-16]. However, few researchers have focused on the differences in the DLA among each component and among various responses [17]. Eurocodes first noted that the dynamic factor of the moment is larger than that of the shear force [18]. Taking a cable-stayed CFST arch bridge as an example, the DLAs of different components were investigated, and three key influencing parameters were presented, including vehicle loading condition, vehicle speed, and road surface condition [19].

The data show that the DLA plays a vital role in the dynamic performance of a bridge subjected to moving vehicular loads [20,21]. For bridge design, the maximum value of the DLA is adopted for safety considerations. In contrast, for bridge evaluation and assessment, the selection of the same value as the theoretical value can have disastrous consequences. However, it is rare to report the difference between the DLAs of various responses in each component of the arch bridge.

To address this issue, based on an actual CFST arch bridge, in this study, the DLA characteristics are investigated numerically. First, aiming at different structural components, the DLA values obtained at various locations of different structural components are compared in detail, and then the changing regulations of the DLA, considering the influence of different vehicle speeds and various extents of pavement roughness, are summarized and analyzed. Additionally, the relationship between different DLAs obtained by using different response indices is investigated. Finally, some conclusions that are beneficial for evaluating or detecting the condition of CFST arch bridges are drawn.

\section{Description of Bridge Structure}

The bridge adopted in this study is the Yilan Mudan River Bridge, which was completed in 1997 and is the first CFST arch bridge in northeastern China (Figure 1) [22]. The total length of the bridge is $507 \mathrm{~m}$, and its width is $12.5 \mathrm{~m}$. There are two $108 \mathrm{~m}$ main spans, four $58 \mathrm{~m}$ approach spans in the Jiamusi direction, and three $8 \mathrm{~m}$ approach spans in the Harbin direction.

The main bridge selected in this paper is shown in Figures 2 and 3. This bridge is a half-through arch bridge with $100 \mathrm{~m}$ net span and $25 \mathrm{~m}$ net rise (the rise-span ratio is $1 / 4)$. The main arch rib line is catenary, and the arch axis coefficient is 1.756; its section is a triangular space truss structure composed of three CFSTs. The suspender consists of a steel wire with a polyethylene jacket. Some small $T$ beams are used for the main girder supported on the transversal beam. In addition, there are three wind bracings between the two main arch ribs. The concrete grade is C50 and C30, the steel type is $16 \mathrm{Mn}$, and the design strength of the steel wire is $1600 \mathrm{MPa}$. The basic parameters of the materials used in the bridge are shown in Table 1.

The completion of the Yilan Mudan River Bridge has led to the vigorous development of the local economy. Because of this rapid economic development, there has been a surge in traffic flow, and, thus, the vehicle weight is seriously overloaded. Therefore, the bridge is in the long-term overloaded situation, which means that the bridge vibration cannot be ignored.

It should be emphasized that this bridge is very famous in China. For the sake of permeability, the original bridge has no wind bracing, which is also the first CFST arch bridge in China without wind bracing. However, due to the occurrence of a variety of issues, many subsequent reinforcements and transformations have been performed during these years.

\section{Vehicle-Bridge Coupled Vibration}

For the highway bridge, the moving vehicle load is one of the main loads during its operation. When a vehicle traverses the bridge at a certain speed, the bridge will vibrate under the excitation of the vehicle. In turn, the vibration of the bridge is also an excitation for the vehicle. There are mutual influences between vehicles and bridges, and the resulting vibration is called the vehicle-bridge coupled vibration [23].

The finite element analysis of this CFST arch bridge is carried out with ANSYS (Figure 4). Three-dimensional beam elements are used for modelling the arc ribs, wind bracings, transversal beams, longitudinal beams, and piers. The suspenders are modelled by using three-dimensional truss elements. The beam element with six degrees of freedom (DOFs) at each node and truss element with three DOFs at each node have been adopted in the finite element model. There are a total of 1911 nodes and 3803 elements in the model, including 3777 beam elements and 26 truss elements. The arc ribs and the piers are fixed at the bottom.

The vibration equation of the bridge structure can be obtained from the structural dynamics, which is shown in the following equation:

$$
\left[M_{b}\right]\left\{\ddot{U}_{b}\right\}+\left[C_{b}\right]\left\{\dot{U}_{b}\right\}+\left[K_{b}\right]\left\{U_{b}\right\}=\left\{F_{b}\right\},
$$

where $\left\{F_{b}\right\}$ represents the force acting on the bridge, which is caused by the moving vehicles; $\left[M_{b}\right]$ represents the mass matrix of the bridge, $\left[C_{b}\right]$ represents the damping matrix of the bridge, and $\left[K_{b}\right]$ represents the stiffness matrix of the bridge. In addition, $\left\{U_{b}\right\}$ is the vibration displacement of the bridge, $\left\{\dot{U}_{b}\right\}$ is the vibration velocity of the bridge, and $\left\{\ddot{U}_{b}\right\}$ is the vibration acceleration of the bridge.

To verify the bridge model established by the finite element software ANSYS, the natural frequencies calculated by the model are compared with those tested by the dynamic fielding test. Low-order modes are more important and easily tested. Therefore, the first two transversal bending modes and the first two vertical bending modes are selected. The modal analysis results calculated by the finite element model are shown in Figure 5, and the results are compared in Table 2. 


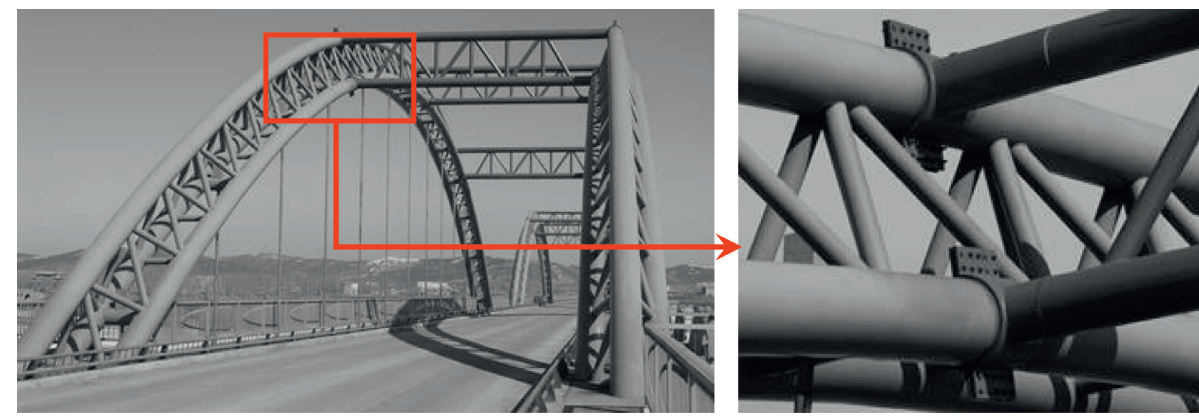

Figure 1: Photos of the bridge.

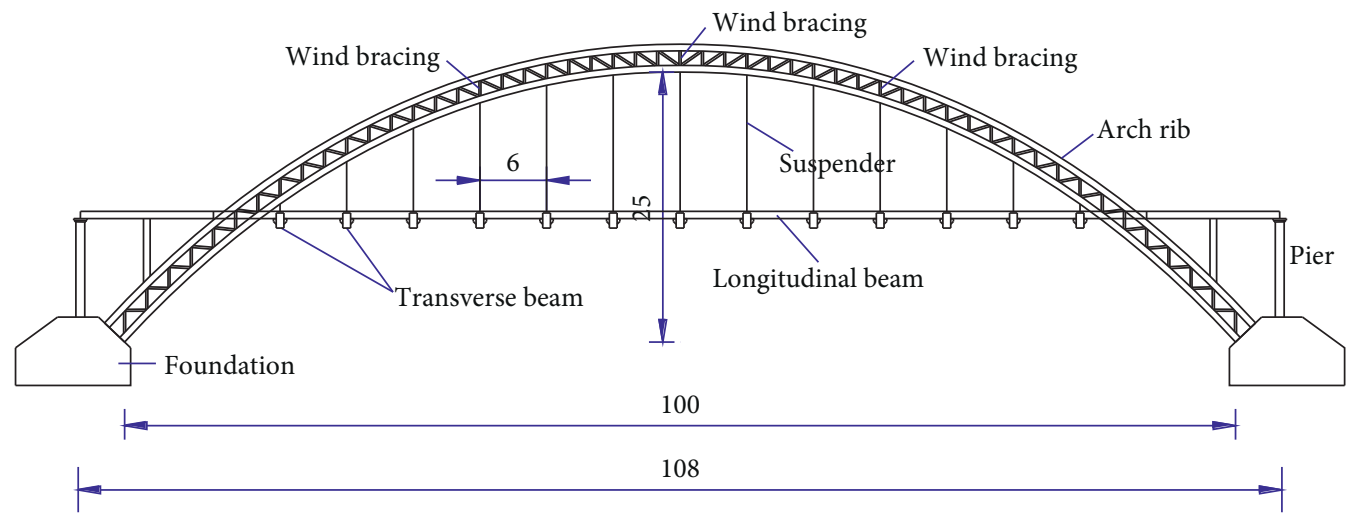

FIgURE 2: Elevation view of the main bridge (unit: $\mathrm{m}$ ).



(a)

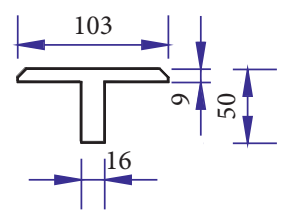

(b)

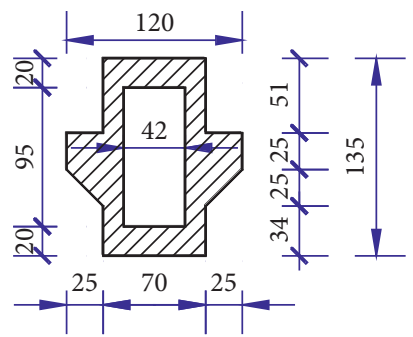

(c)

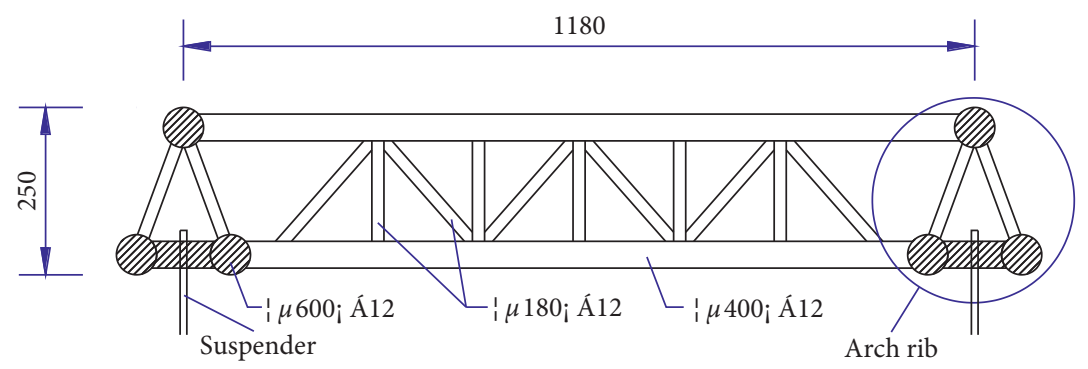

(d)

FIgURe 3: Component drawings (unit: $\mathrm{cm}$ ): (a) arch rib; (b) longitudinal beam; (c) transverse beam; and (d) details of wind bracing.

The largest relative error in Table 2 between the tested natural frequency and the calculated natural frequency is $3.78 \%$, which is smaller than $5 \%$. In other words, the bridge model in this paper is correct and effective. In addition, the damping ratio is 0.02 , which is gained by the pulsation test. 
TABLE 1: The basic information about the materials.

\begin{tabular}{lcccc}
\hline Materials & $\begin{array}{c}\text { Young's modulus } \\
(\mathrm{MPa})\end{array}$ & Poisson's ratio & $\begin{array}{c}\text { Unit weight } \\
\left(\mathrm{kN} / \mathrm{m}^{3}\right)\end{array}$ & Components \\
\hline Concrete C50 & $3.45 \times 10^{4}$ & 0.2 & 26 & Transversal and longitudinal beams, concrete in steel \\
Concrete C30 & $3.00 \times 10^{4}$ & 0.2 & 26 & Pubes \\
Steel 16 Mn & $2.06 \times 10^{5}$ & 0.3 & 78.5 & Piers \\
Steel wire & $1.95 \times 10^{5}$ & 0.3 & 78.5 & Arch ribs, wind bracings \\
\end{tabular}

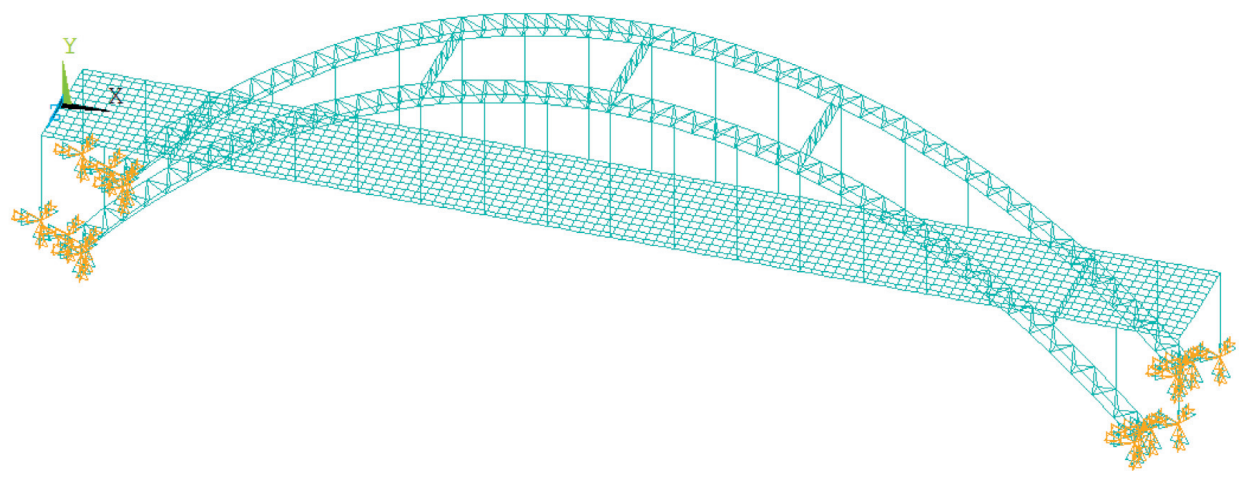

(a)

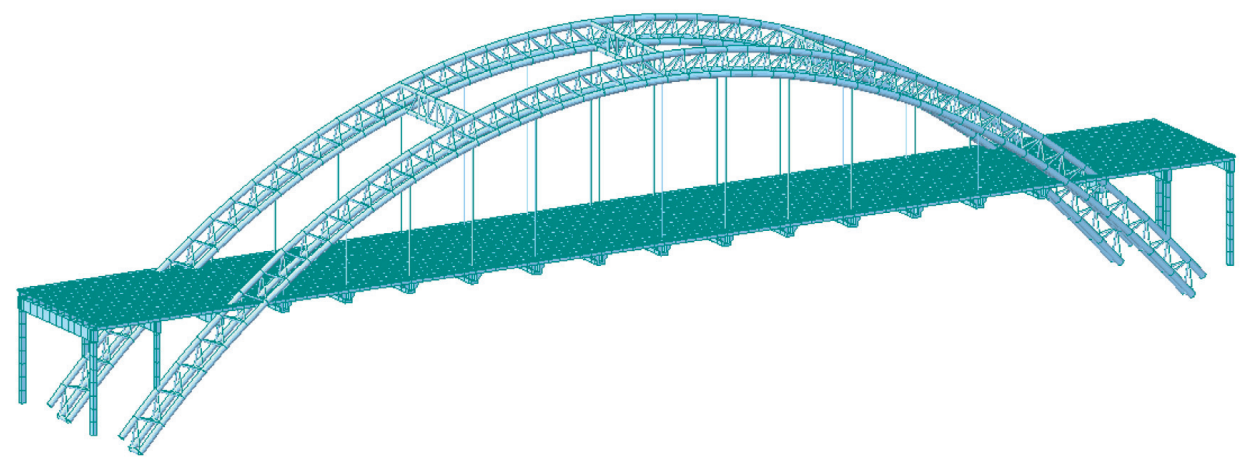

(b)



(c)

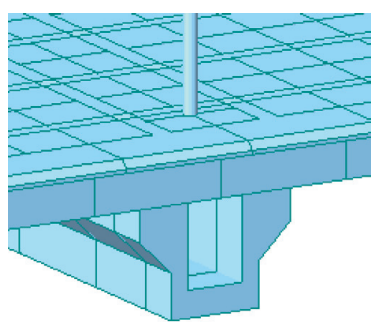

(d)

FIGURE 4: Finite element model: (a) spatial grillage model; (b) spatial grillage model with visual shapes; (c) wind bracing; (d) transverse beam.

The vehicle with multiaxles is adopted and the spatial model is established. Several assumptions are made about the vehicle model. The wheel and the bridge will contact with each other tightly all the time. Only vertical effects between the vehicle and the bridge are considered while longitudinal and transverse effects are ignored. The vehicle body and all wheels are assumed as rigid with corresponding masses while the spring and the damper are linear. The vehicle model can be seen in Figure 6.
The dynamic equations of the vehicle can be written as

$$
\left[M_{V}\right]\left\{\ddot{Z}_{V}\right\}+\left[C_{V}\right]\left\{\dot{Z}_{V}\right\}+\left[K_{V}\right]\left\{Z_{V}\right\}=\left\{F_{V}\right\},
$$

where the $\left\{F_{V}\right\}$ is the load vector induced by the bridge, $\left[M_{V}\right],\left[C_{V}\right]$, and $\left[K_{V}\right]$ are, respectively, the mass matrix, damping matrix, and stiffness matrix of the vehicle. Furthermore, $\left\{Z_{V}\right\}$ is the displacement of the vehicle, the first derivative of the displacement is the vibration velocity, and 


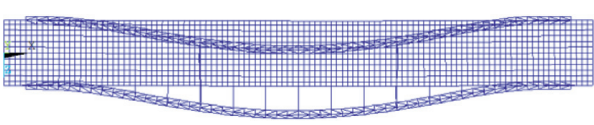

(a)

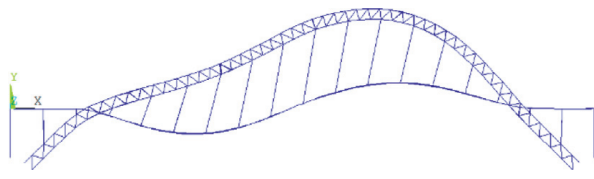

(c)

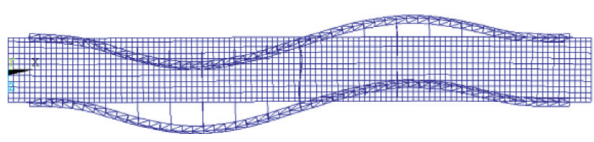

(b)



(d)

FIGURE 5: Modal analysis results: (a) first-order transverse bending mode $\left(1^{\text {st }} \mathrm{TBM}\right)$; (b) second-order transverse bending mode $\left(2^{\text {nd }}\right.$ TBM); (c) first-order vertical bending mode $\left(1^{\text {st }} \mathrm{VBM}\right)$; (d) second-order vertical bending mode $\left(2^{\text {nd }} V B M\right)$.

TABle 2: Dynamic characteristics of the bridge.

\begin{tabular}{lccc}
\hline Vibration modes & Calculated natural frequencies $(\mathrm{Hz})$ & Tested natural frequencies $(\mathrm{Hz})$ & Relative error $(\%)$ \\
\hline $1^{\text {st }}$ TBM & 0.595 & 0.608 & 2.18 \\
$2^{\text {nd }}$ TBM & 1.639 & 1.701 & 3.78 \\
$1^{\text {st }}$ VBM & 1.598 & 1.602 & 0.25 \\
$2^{\text {nd }}$ VBM & 2.301 & 2.362 & 2.65 \\
\hline
\end{tabular}

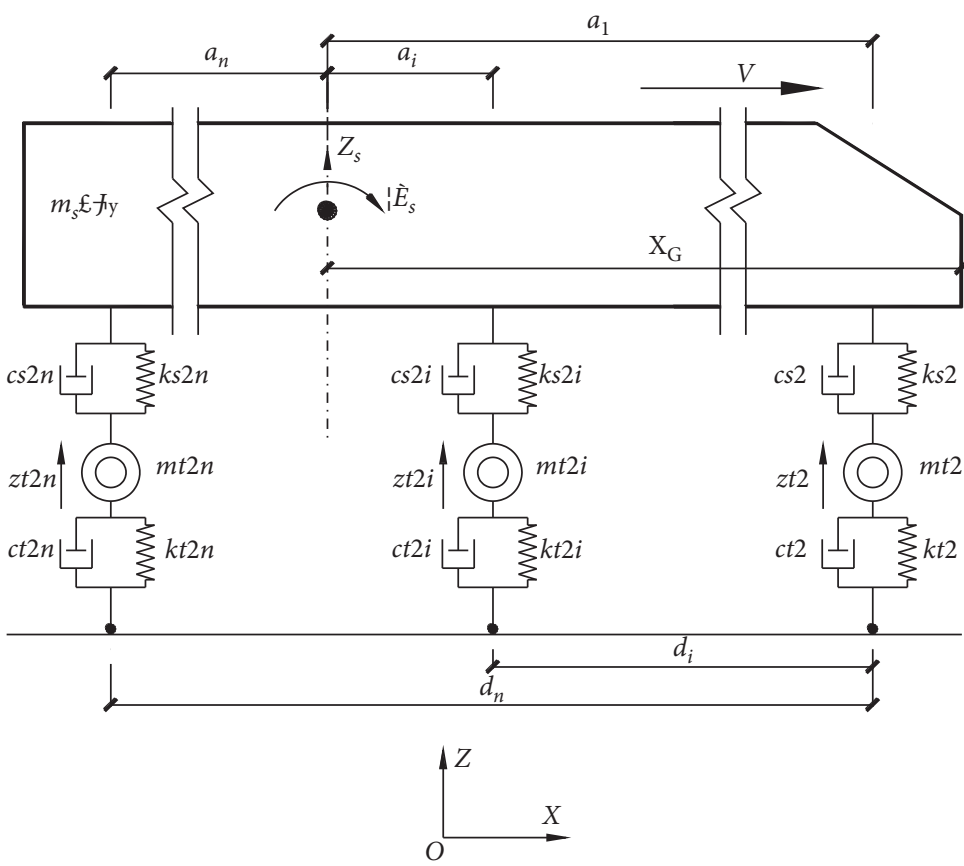

(a)

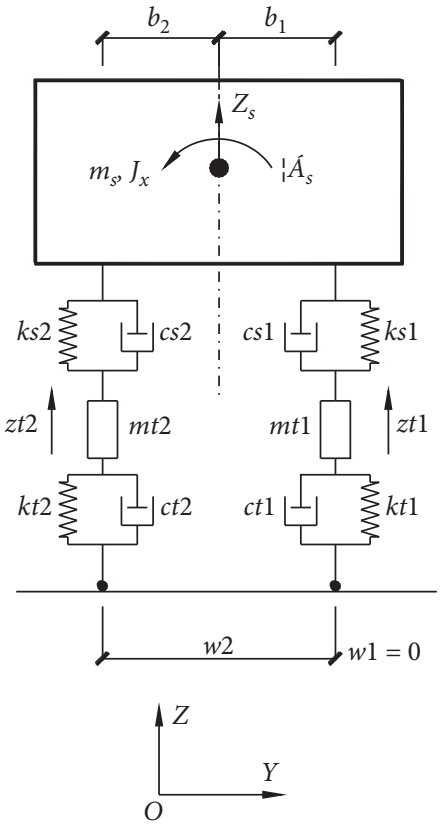

(b)

FIgURE 6: Vehicle model.

the second derivative of the displacement is the vibration acceleration.

The mass matrix, displacement vector, and load vector of the vehicle model are, respectively, shown as follows:

$$
\left[M_{V}\right]=\operatorname{diag}\left\{m_{s}, J_{y}, J_{x}, m_{t 1}, m_{t 2}, m_{t 3}, \ldots, m_{t 2 n}\right\}
$$

where $m_{s}$ is the mass of the vehicle body, $m_{t i}$ is the mass of the $i$ th vehicle wheel, and $J_{\mathrm{y}}$ and $J_{\mathrm{x}}$ are, respectively, the moment of inertia of longitudinal swing and transversal swing:

$$
\left\{U_{V}\right\}=\operatorname{col}\left\{U_{s}, \theta_{s}, \alpha_{s}, U_{t 1}, U_{t 2}, \ldots, U_{t 2 n}\right\},
$$

where $U_{s}$ is the vertical vibration degree of the vehicle body, $U_{t i}$ is the vertical vibration degree of the $i$ th vehicle wheel, and $\theta_{s}$ and $\alpha_{s}$ are, respectively, the vibration degree of longitudinal swing and transversal swing: 


$$
\begin{aligned}
\left\{F_{V}\right\}= & \operatorname{col}\left\{0,0,0, k_{t 1} \Delta_{1}+c_{t 1} \dot{\Delta}_{1}, k_{t 2} \Delta_{2}\right. \\
& \left.+c_{t 2} \dot{\Delta}_{2}, \ldots, k_{t 2 n} \Delta_{2 n}+c_{t 2 n} \dot{\Delta}_{2 n}\right\}
\end{aligned}
$$

where $\Delta_{i}$ is the relative displacement of the contact point between wheel and bridge deck and $k_{t i}$ and $c_{t i}$ are, respectively, the stiffness coefficient and damping coefficient of the $i$ th vehicle wheel.

The damping matrix of the vehicle model is divided into four parts by taking the boundary line between the vehicle body and the wheel:

$$
\begin{aligned}
& {\left[C_{V}\right]=\left[\begin{array}{ll}
C_{V 11} & C_{V 12} \\
C_{V 21} & C_{V 22}
\end{array}\right],} \\
& {\left[C_{V 11}\right]=\left[\begin{array}{ccc}
\sum_{i=1}^{n}\left(c_{s 2 i-1}+c_{s 2 i}\right) & -\sum_{i=1}^{n} a_{i}\left(c_{s 2 i-1}+c_{s 2 i}\right) & -\sum_{i=1}^{n}\left(b_{1} c_{s 2 i-1}+b_{2} c_{s 2 i}\right) \\
-\sum_{i=1}^{n} a_{i}\left(c_{s 2 i-1}+c_{s 2 i}\right) & \sum_{i=1}^{n} a_{i}^{2}\left(c_{s 2 i-1}+c_{s 2 i}\right) & -\sum_{i=1}^{n}\left(b_{1} a_{i} c_{s 2 i-1}+b_{2} a_{i} c_{s 2 i}\right) \\
-\sum_{i=1}^{n}\left(b_{1} c_{s 2 i-1}+b_{2} c_{s 2 i}\right) & -\sum_{i=1}^{n}\left(b_{1} a_{i} c_{s 2 i-1}+b_{2} a_{i} c_{s 2 i}\right) & \sum_{i=1}^{n}\left(b_{1}^{2} c_{s 2 i-1}+b_{2}^{2} c_{s 2 i}\right)
\end{array}\right],} \\
& {\left[C_{V 12}\right]=\left[\begin{array}{cccc}
-c_{s 1} & -c_{s 2} & \cdots & -c_{s 2 n} \\
a_{1} c_{s 1} & a_{1} c_{s 2} & \cdots & a_{n} c_{s 2 n} \\
-b_{1} c_{s 1} & -b_{2} c_{s 2} & \cdots & -b_{2} c_{s 2 n}
\end{array}\right] \text {, }} \\
& {\left[C_{V 21}\right]=\left[\begin{array}{ccc}
-c_{s 1} & a_{1} c_{s 1} & -b_{1} c_{s 1} \\
-c_{s 2} & a_{1} c_{s 2} & -b_{2} c_{s 2} \\
\vdots & \vdots & \vdots \\
-c_{s 2 n} & a_{n} c_{s 2 n} & -b_{1} c_{s 2 n}
\end{array}\right]} \\
& {\left[C_{V 22}\right]=\left[\begin{array}{cccc}
c_{s 1}+c_{t 1} & 0 & \cdots & 0 \\
0 & c_{s 2}+c_{t 2} & \cdots & 0 \\
\vdots & \vdots & \ddots & \vdots \\
0 & 0 & \cdots & c_{s 2 n}+c_{t 2 n}
\end{array}\right]}
\end{aligned}
$$

where $k_{s i}$ and $c_{s i}$ are, respectively, the stiffness coefficient and damping coefficient of the suspension system of the $i$ th vehicle wheel.

Similarly, when calculating the stiffness matrix of the vehicle model, $C$ and $c$ in the damping matrix are changed to $K$ and $k$, respectively, which will not be discussed here.

The pavement roughness is the main excitation of vibration, which plays an important role in the analysis of vehicle-bridge coupled vibration. The pavement roughness model in this paper is expressed as follows [24]:

$$
S(\omega)=\alpha \omega^{-\beta}, \quad \omega_{l}<\omega<\omega_{u}
$$

where $S(\omega)$ denotes the power spectral density function, $\alpha$ represents the roughness coefficient, $\beta$ represents the frequency index, $\omega$ represents the spatial frequency, and $\omega_{l}$ and $\omega_{u}$ are the lower limit and upper limit of the spatial frequency, respectively.

The pavement roughness is simulated as a steady-state Gaussian random process. Therefore, the inverse Fourier transform of equation (11) can be obtained as follows:

$$
X(t)=\sum_{i=1}^{N} \sqrt{4 S\left(\omega_{i}\right) \Delta \omega} \cos \left(\omega_{i} t-\theta_{i}\right),
$$

where $\theta_{i}$ is a random phase angle, and its value varies from 0 to $2 \pi$. Some simulation samples of the pavement roughness are illustrated in Figure 7.

\section{Dynamic Load Allowance of the Bridge}

Due to the difficulties in solving nonlinear problems, it is challenging to study the dynamic response of bridges under the load of moving vehicles, especially for bridge engineers. Many tests have shown that the dynamic responses are indeed larger than the static responses. For this reason, the DLA is introduced in the national specifications. The bridge dynamic responses caused by the moving vehicular loads have been investigated. Furthermore, the influencing factors of the DLA have been analyzed, including the parameters of bridge structures, the type of vehicles, the speed of vehicles, pavement roughness, and so forth. 


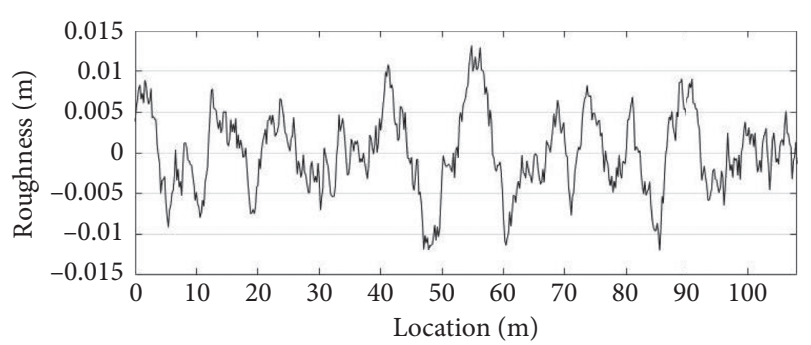

(a)

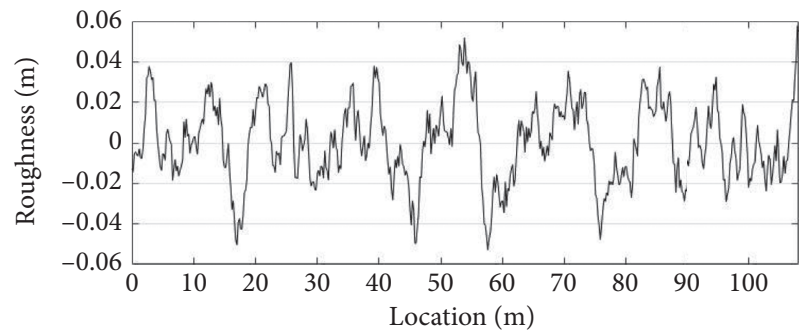

(c)

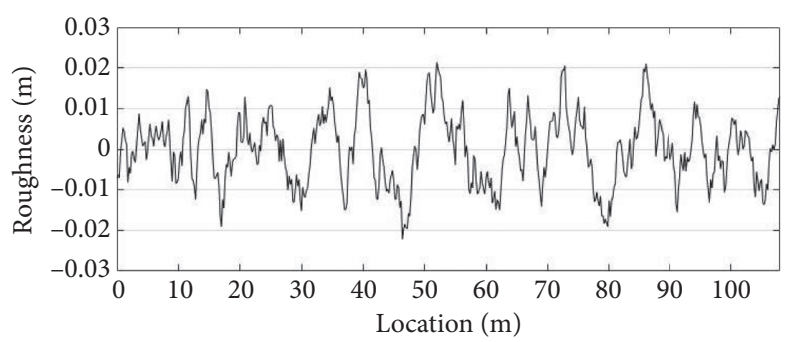

(b)

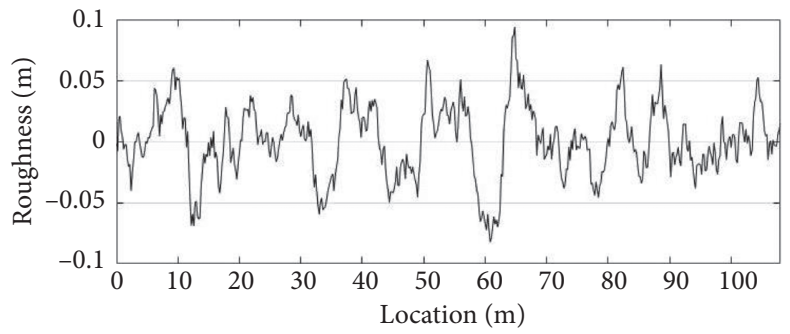

(d)

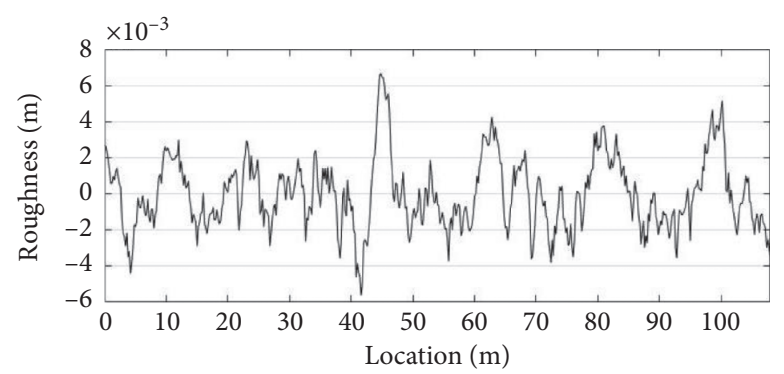

(e)

Figure 7: Pavement roughness: (a) very good $\left(\alpha=0.1 \times 10^{-6}\right)$; (b) $\operatorname{good}\left(\alpha=0.5 \times 10^{-6}\right)$; (c) average $\left(\alpha=2 \times 10^{-6}\right)$; (d) poor $\left(\alpha=10 \times 10^{-6}\right)$; (e) very poor $\left(\alpha=20 \times 10^{-6}\right)$.

4.1. Dynamic Responses of a Bridge. In this study, eight vehicle speeds are adopted, respectively, ranging from $5 \mathrm{~m} / \mathrm{s}$ to $40 \mathrm{~m} / \mathrm{s}$ with intervals of $5 \mathrm{~m} / \mathrm{s}$. Five different types of pavement roughness are selected, which can be divided into 5 conditions: very good, good, average, poor, and very poor. The pavement roughness has an obvious influence on the dynamic response of the bridge. Even under the same pavement roughness, the corresponding result has a certain degree of randomness. Therefore, in this paper, the simulation for each kind of pavement roughness is run 20 times, and then the average value of the DLAs obtained from these 20 runs is calculated, which shows that the result is sufficiently accurate $[25,26]$. A three-axle vehicle is adopted. The weight is 55 tons; other parameters can be seen in [27]. The vehicle travels along with the center lane of the bridge.

The dynamic responses of different bridge components are analyzed, including the main girder, main rib arch, and suspenders. It can be seen that the bridge is a symmetrical structure, so only half of the components are studied. A total of 15 sections are selected in Figure 8.

According to the characteristics of different components, the concerned dynamic responses are not completely consistent. For the main girders, the displacement and bending moment are considered. For the main arch ribs, the displacement, bending moment, and axial force are considered. For the suspenders, only the axial force is considered. Some dynamic responses are demonstrated in Figure 9.

Figure 9 shows that the dynamic responses of the main girders and arch ribs are quite sensitive to the vehicle locations, especially their maximum values. In contrast, the dynamic responses of the suspenders are not evidently changed. However, the cycle number of the suspenders is more obvious than that of the main girders and arch ribs. In other words, the fatigue of the suspenders should be given much attention.

4.2. DLAs of Different Components. As the vault section of the half-through arch bridge is high, it is not convenient to arrange the sensors. In particular, the traditional displacement sensor needs to find a fixed point, which is obviously not suitable for arch rib testing. Noncontact displacement sensors can be adopted, but they are so expensive. Therefore, considering that the main girder is more convenient for arranging the sensors, we hope to find the relationship between the DLA of the arch ribs and that of the main girders.

Two sections, the vault section $(R)$ and midspan section $(G)$, are selected for investigating the DLA of the displacement. With various vehicle travelling speeds and 


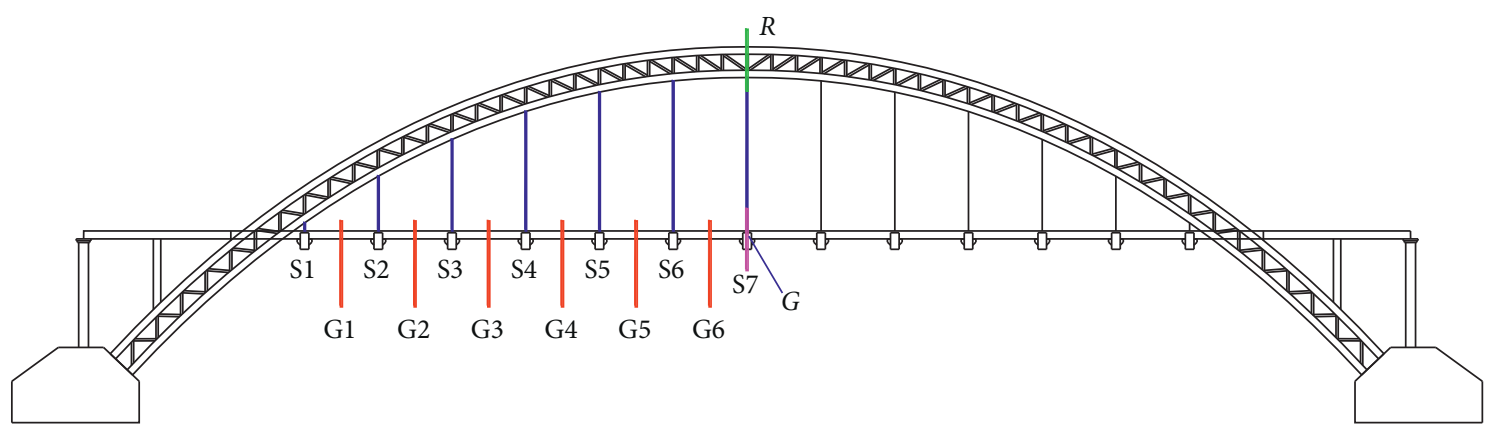

FIgURE 8: Signs of the components and sections.

different pavement roughnesses, the differences between these two DLAs are discussed in detail. The results are shown in Figure 10.

In Figure 10, when the deck condition is not worse than good, the DLA of the arch rib is less than that of the main girder. With the deterioration of the deck, both DLAs clearly increase. In addition, the DLA of the arch rib increases faster, which makes the DLA of the arch rib greater than that of the main girder when the deck is in a very poor condition, contrary to the conclusion when the deck is in a good condition.

Therefore, in bridge evaluation or detection, for a new bridge, the deck condition is always good enough, and only the DLA of the main girder is tested, which can represent the maximum value of the measured DLAs. However, if the deck condition is poor in old bridges, then the DLA of the arch rib must be tested and will be much larger.

4.3. DLA of the Main Girder. For half-through arch bridges, the sensor arrangement on the main girder is obviously more convenient than that on the arch rib. Therefore, in bridge detection and evaluation, sensors are always arranged on the main girder to test the dynamic response and DLA.

4.3.1. DLA Influenced by the Pavement Roughness and Travelling Speeds. The static analysis results show that the static response of section $G$ is the largest. Therefore, taking section $G$ as the research point, when the vehicle travels with several speeds under the condition of various bridge deck roughness values, the DLA of the displacement and the DLA of the bending moment are calculated (Figure 11). These characteristics are defined as follows:

$$
\operatorname{DLA}(D)=\frac{D_{\text {dynamic }}}{D_{\text {stat }}}-1,
$$

where DLA $(D)$ denotes the dynamic load allowance of the vertical displacement at the main girder, $D_{\text {dynamic }}$ denotes the vertical displacement of the main girder caused by the dynamic loads of the vehicles, and $D_{\text {stat }}$ denotes the vertical displacement of the main girder caused by the static vehicle loads:

$$
\operatorname{DLA}(M)=\frac{M_{\text {dynamic }}}{M_{\text {stat }}}-1,
$$

where DLA $(M)$ denotes the dynamic load allowance of the bending moment on the main girder, $M_{\text {dynamic }}$ denotes the bending moment of the main girder caused by the dynamic loads of the vehicles, and $M_{\text {stat }}$ is the bending moment of the main girder caused by the static vehicle loads.

In Figure 11, the pavement roughness has a great impact on the DLAs. Both the DLA $(D)$ and the DLA $(M)$ increase significantly as the pavement condition worsens. The DLA $(M)$ substantially increases with increasing vehicle travelling speed, which is not obvious. When the bridge deck is in a poor condition, the DLA $(M)$ exhibits two critical peaks, which correspond to vehicle travelling speeds of $10 \mathrm{~m} / \mathrm{s}$ and $35 \mathrm{~m} / \mathrm{s}$. However, the DLA $(D)$ does not necessarily increase with increasing vehicle travelling speed, and its sensitive speeds are $20 \mathrm{~m} / \mathrm{s}$ and $30 \mathrm{~m} / \mathrm{s}$. One possible interpretation may be that the dynamic responses of the bridge under the load of moving vehicles are related to three frequencies: the natural frequency of the bridge, the natural frequency of the vehicle, and the disturbance frequency that varies with the speed of the vehicle.

4.3.2. DLAs in Different Locations of the Main Girder. The results above show that the sensitive speeds are $20 \mathrm{~m} / \mathrm{s}$ and $30 \mathrm{~m} / \mathrm{s}$. Therefore, taking sections G1 to G6 as the research points when the vehicle passes the bridge at these two speeds under the condition of various bridge deck roughnesses, the DLA of the displacement and the DLA of the bending moment are calculated (Figure 12).

In Figure 12, both the $\operatorname{DLA}(D)$ and $\operatorname{DLA}(M)$ vary greatly in different locations. However, the differences in the DLAs among these locations are negligibly influenced by the pavement roughness. The DLAs in different locations can vary by nearly a factor of two in most cases. Therefore, in bridge detection, sensors cannot be optionally arranged, and the test results should be compared with the theoretical value of the DLA of the corresponding position, rather than directly with the design value of the DLA.

4.3.3. DLAs for the Different Responses of the Main Girder. In the traditional testing techniques, the displacement test requires a fixed point while the strain test does not. For large-span bridges, especially crossing rivers, lakes, and seas or the piers that are high, the fixed point of the displacement sensor is difficult to find. Therefore, bridge engineers hope to 


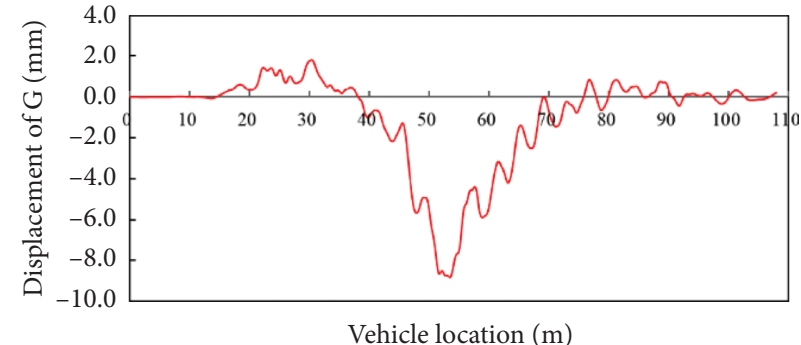

(a)

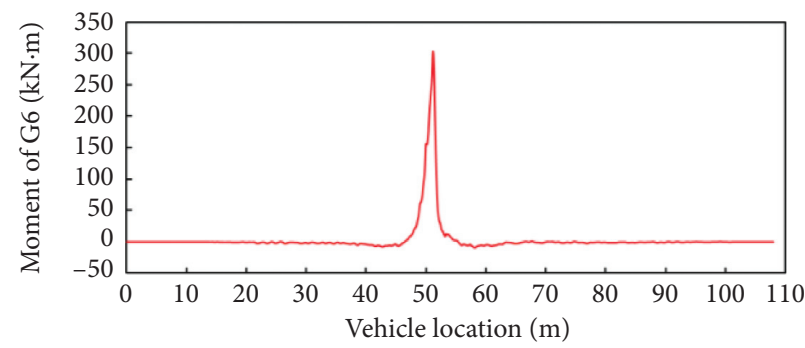

(c)

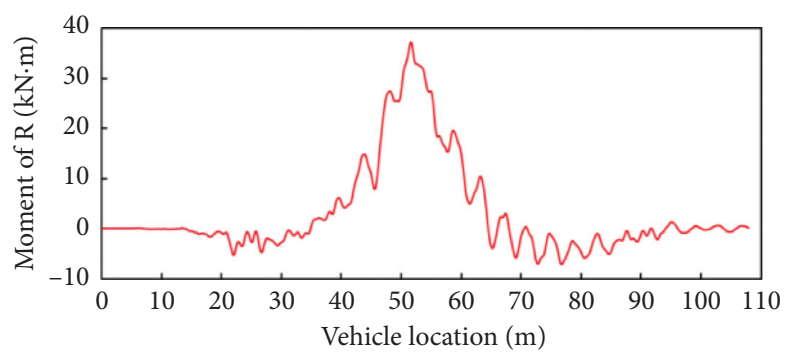

(e)

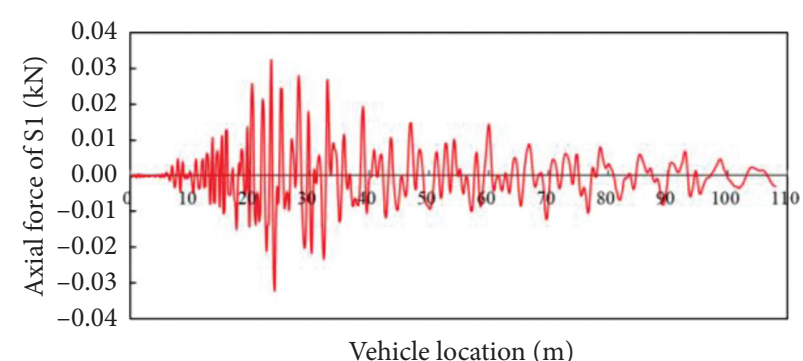

(g)

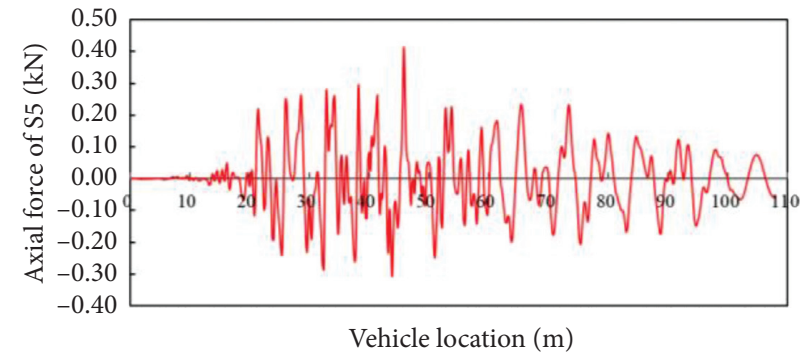

(i)

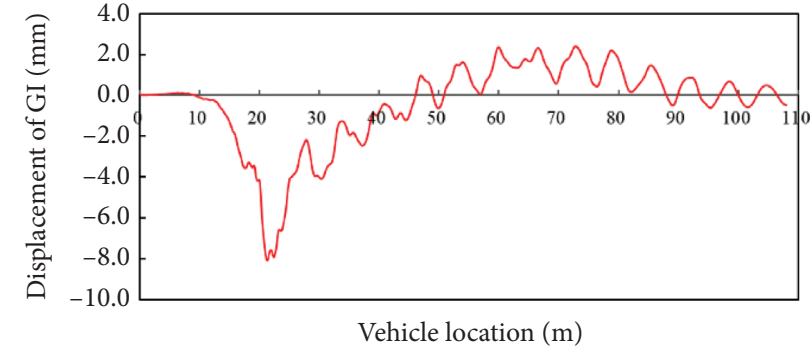

(b)

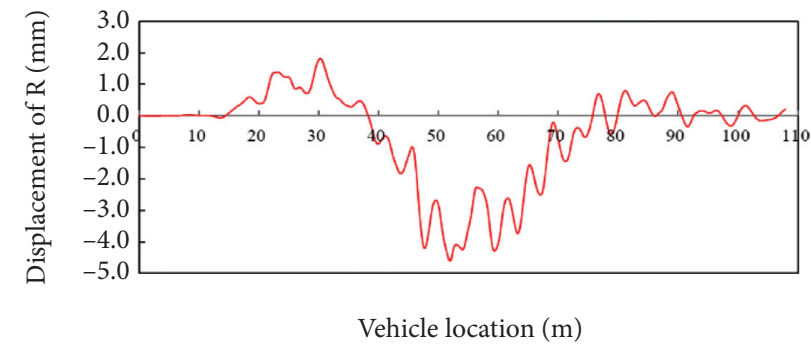

(d)

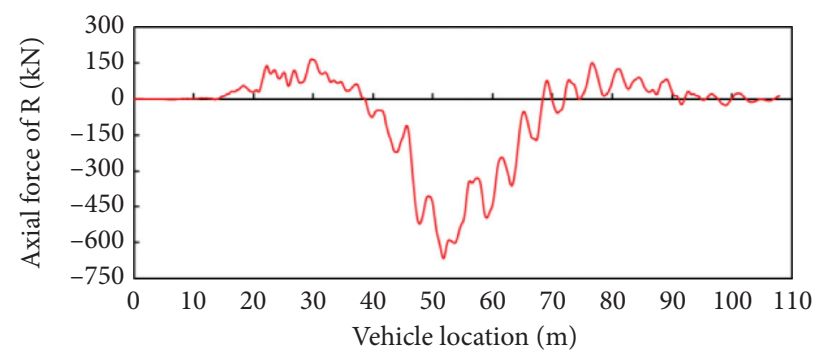

(f)

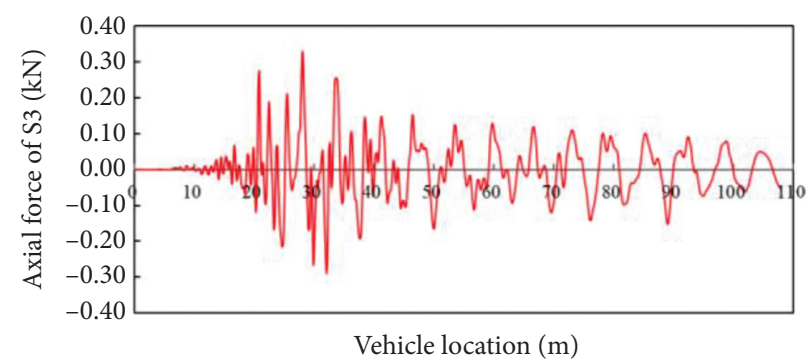

(h)

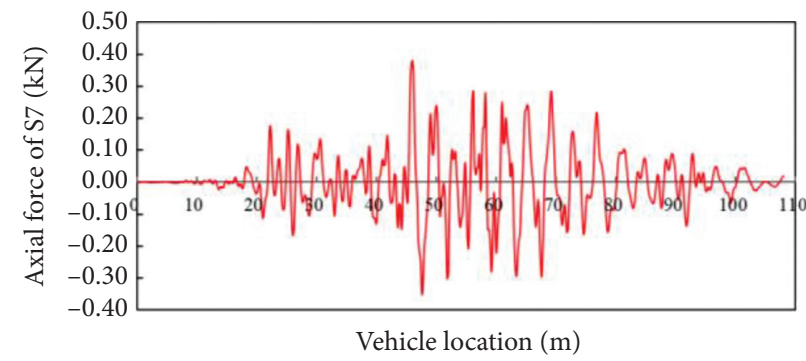

(j)

Figure 9: Dynamic responses ( $v=15 \mathrm{~m} / \mathrm{s}$, pavement roughness is the average): (a) displacement of $G$; (b) displacement of G1; (c) moment of G6; (d) displacement of $R$; (e) moment of $R$; (f) axial force of $R$; (g) axial force of S1; (h) axial force of S3; (i) axial force of S5; (j) axial force of S7. 

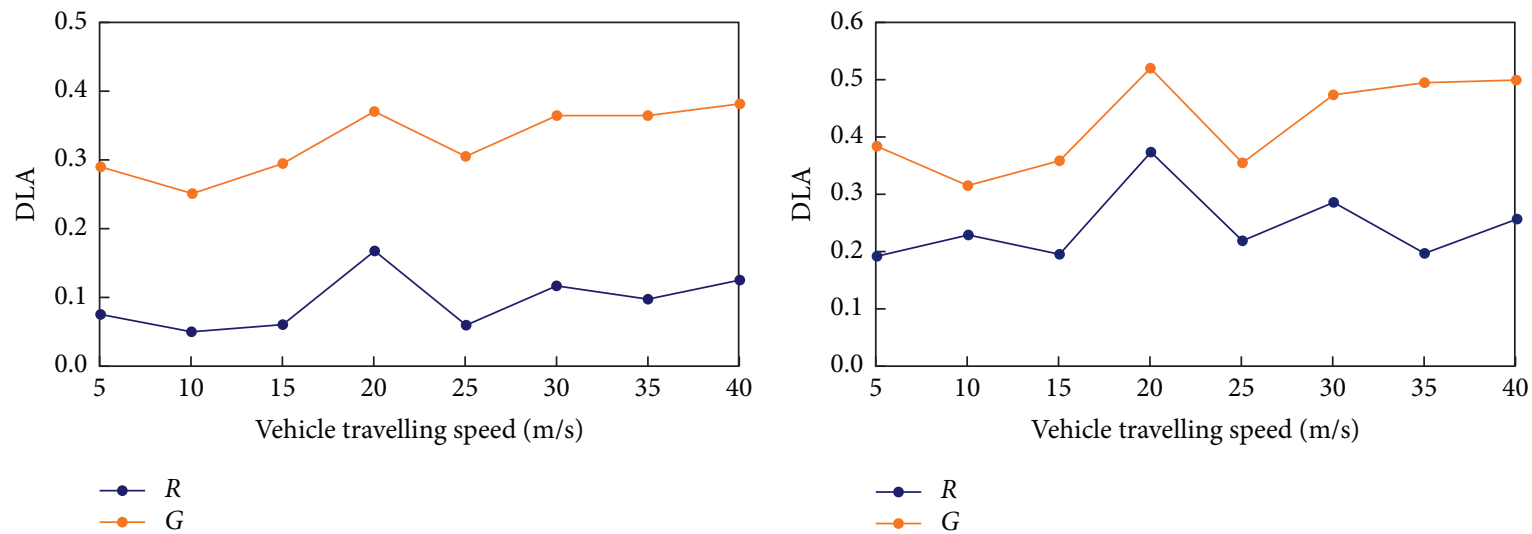

(a)

(b)
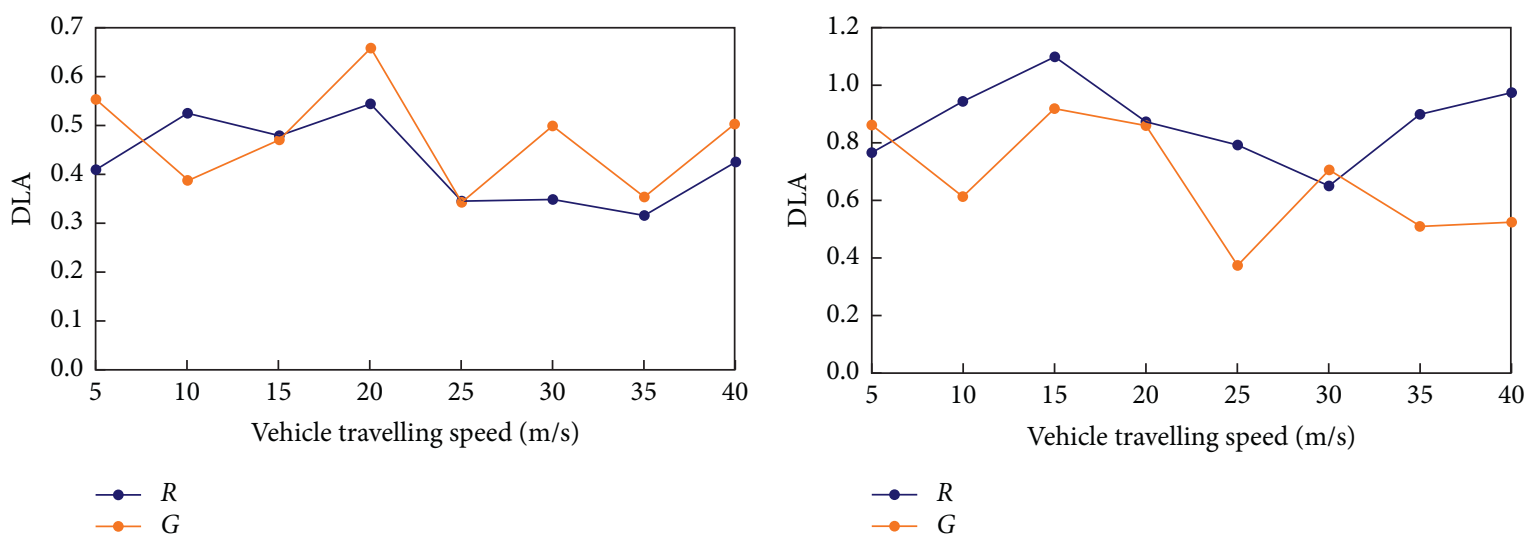

(c)

(d)

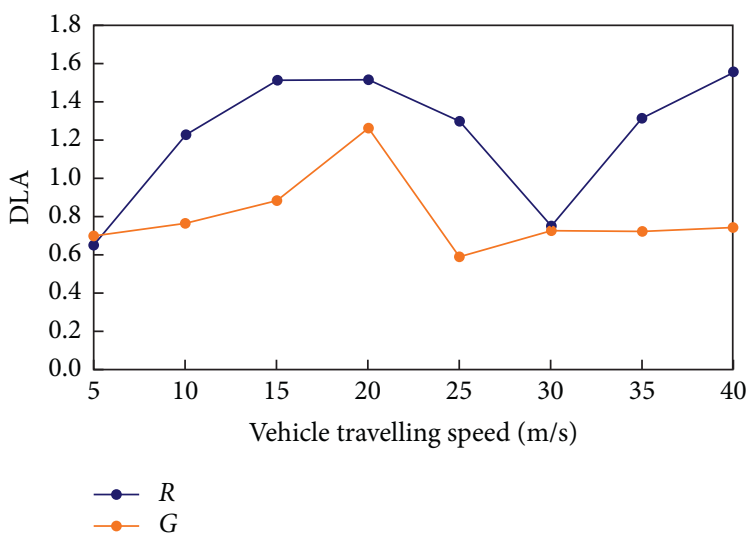

(e)

Figure 10: DLAs for the displacement of different components with various pavement roughnesses: (a) very good; (b) good; (c) average; (d) poor; (e) very poor.

replace displacement test results with strain test results. However, according to the above analysis, these two tests are not completely consistent. To this end, the ratio of these two DLAs is introduced and defined as follows:

$$
\operatorname{DLA}\left(\frac{M}{D}\right)=\frac{\operatorname{DLA}(M)}{\operatorname{DLA}(D)},
$$

where DLA $(M / D)$ is the ratio between the DLA $(M)$ and the $\operatorname{DLA}(D)$.
Taking the midspan section $G$ with the largest static response of the girder as an example, the calculation DLAs are illustrated in Figure 13.

In Figure 13, the DLA $(M / D)$ decreases as the deck condition worsens and is only slightly influenced by the pavement roughness. When the bridge deck condition is very good or good, the ratio can be approximated to 1.0. However, when the condition of the bridge deck deteriorates to very poor, the ratio is less than 0.4 , which makes the 


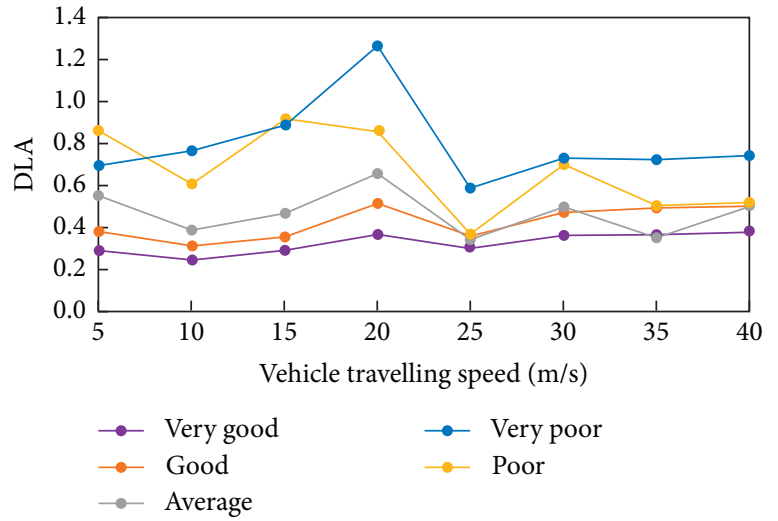

(a)

Figure 11: DLA for the midspan section of the main girder G: (a) DLA of the displacement; (b) DLA of the bending moment.

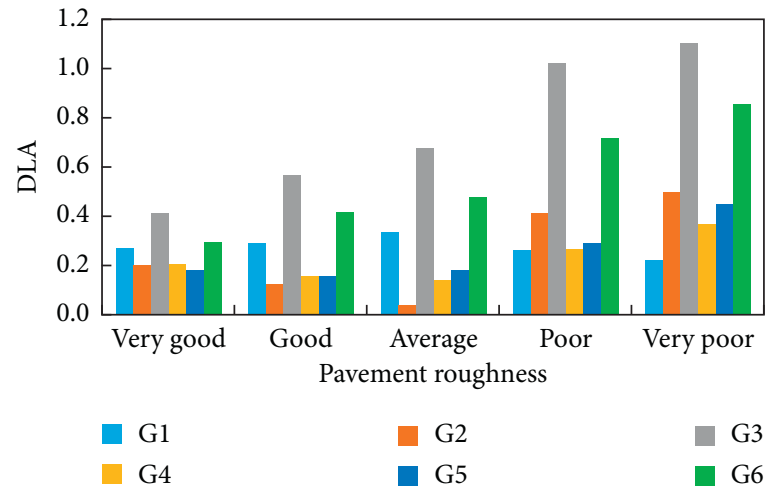

(a)

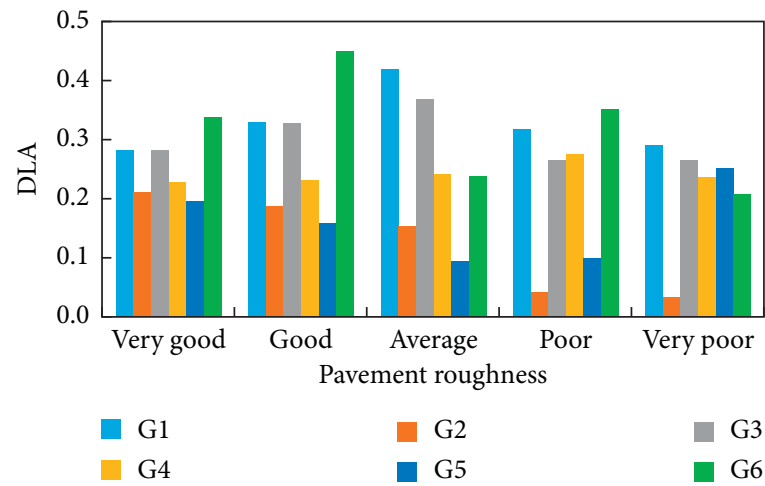

(c)

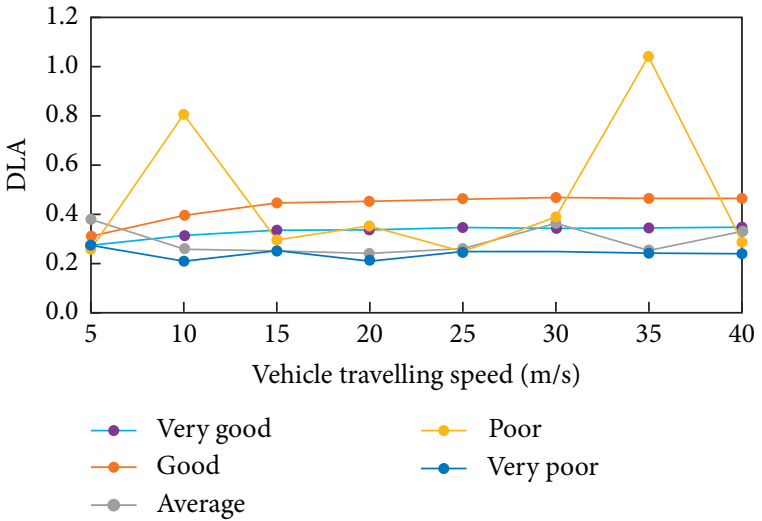

(b)

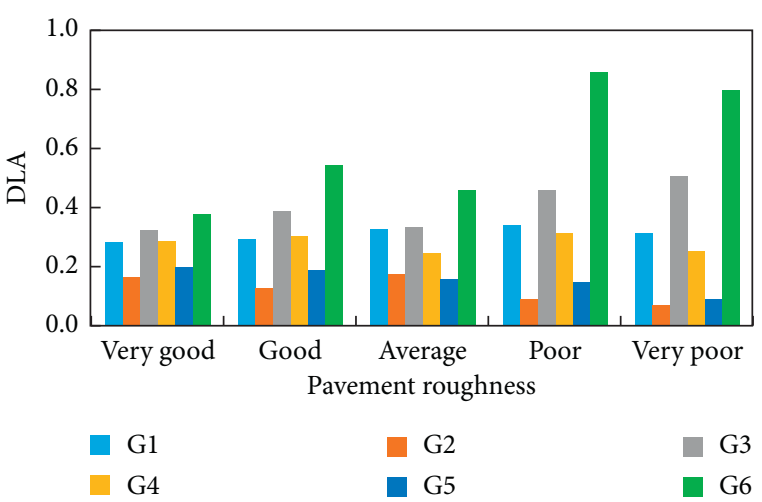

(b)



(d)

Figure 12: DLAs in different locations of the main girder: (a) DLA of the displacement $(v=20 \mathrm{~m} / \mathrm{s}$ ); (b) DLA of the displacement $(v=30 \mathrm{~m} / \mathrm{s})$; (c) DLA of the bending moment $(v=20 \mathrm{~m} / \mathrm{s})$; (d) DLA of the bending moment $(v=30 \mathrm{~m} / \mathrm{s})$.

difference obvious. When the bridge deck condition is average, it can be considered 0.5 . Therefore, it is not possible to replace the displacement test results by the strain test results directly, especially when the deck condition is not good.

4.4. DLA of the Arch Rib. The arch rib is the framework of the main arch ring, and it is the important component of the arch bridge. The vault section and the foot section are two critical sections of the arch bridge. The vault section is adopted as an example in this study to analyze the DLA of section displacement, bending moment, and axial force.

4.4.1. DLA Influenced by the Pavement Roughness and Travelling Speeds. The DLAs of the vault section $(R)$ of the arch rib are illustrated in Figure 14. 


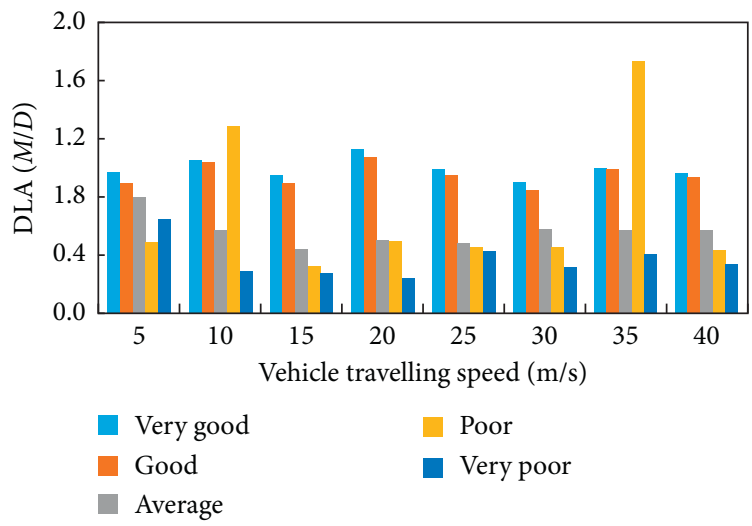

FIGURE 13: DLAs for the different responses of the main girder.



(a)

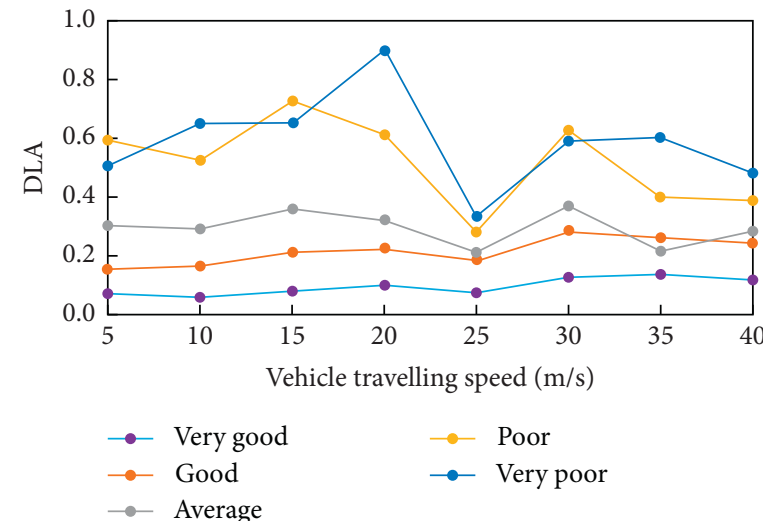

(b)

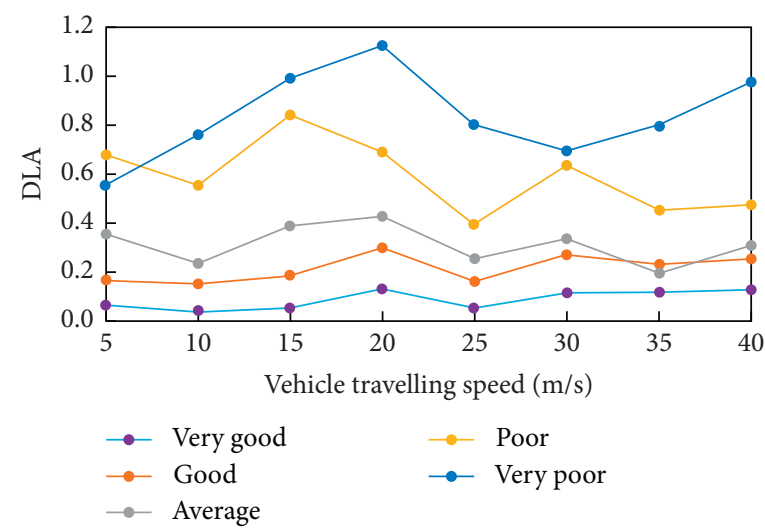

(c)

Figure 14: DLA for the vault section of the arch rib R: (a) DLA of the displacement; (b) DLA of the bending moment; (c) DLA of the axial force.

In Figure 14, the pavement roughness has a great impact on the DLAs. The DLA $(D)$, DLA $(M)$, and DLA $(N)$ increase significantly as the pavement condition worsens. However, the DLA $(D)$ does not show an upward trend with the increase in vehicle speed. When the deck condition is not worse than the average, the sensitive speeds are $20 \mathrm{~m} / \mathrm{s}$ and $30 \mathrm{~m} / \mathrm{s}$, which is consistent with the main girder analysis results above. When the deck condition is very poor, the change in the DLA $(M)$ with speed is more like that of the DLA $(N)$ but is different from that of the DLA $(D)$.
4.4.2. DLAs for the Different Responses of the Rib Arch. To explore the relationship between the DLAs of different responses, in addition to the DLA $(M / D)$ introduced above, the parameter DLA $(N / D)$ is introduced here, that is, the ratio of DLA $(N)$ to DLA $(D)$ :

$$
\operatorname{DLA}\left(\frac{N}{D}\right)=\frac{\operatorname{DLA}(N)}{\operatorname{DLA}(D)}
$$

where DLA $(N)$ is the dynamic load allowance of the axial force. 


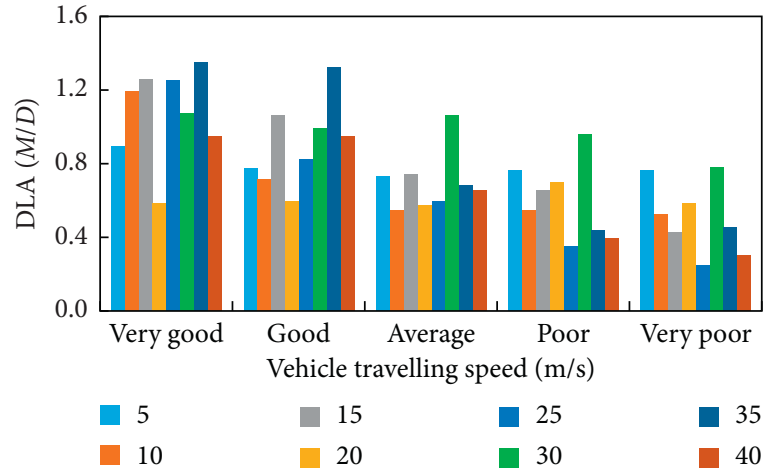

(a)

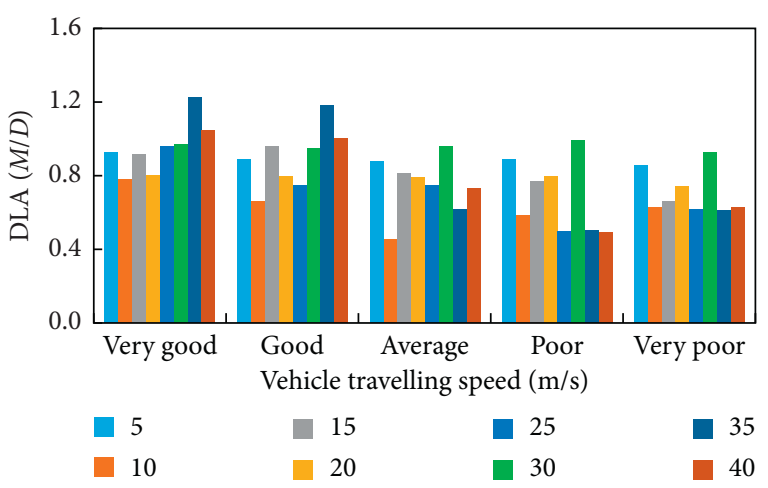

(b)

Figure 15: DLAs for the different responses of the arch rib: (a) DLA M/D and (b) DLA N/D.

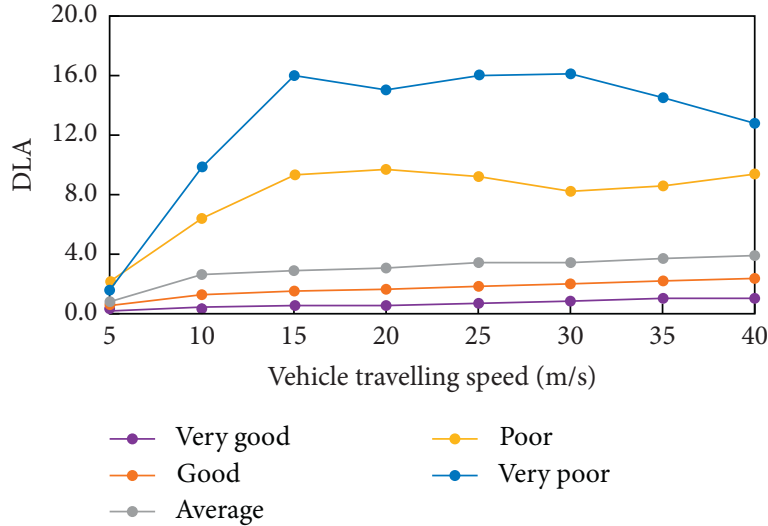

(a)

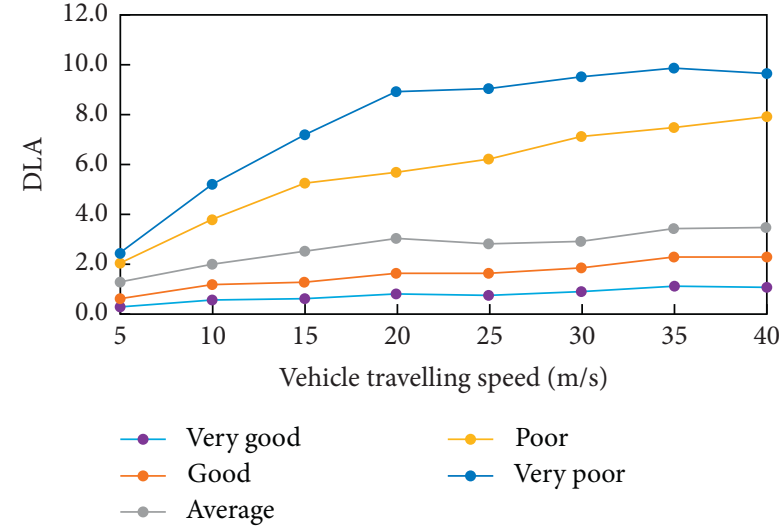

(b)

FIgURE 16: DLA of the suspender: (a) DLA of the shortest suspender (S1); (b) DLA of the longest suspender (S7).

The calculation results of the DLAs of the arch rib are demonstrated in Figure 15.

In Figure 15, the DLA $(M / D)$ and the DLA $(N / D)$ slightly decrease as the deck condition worsens. However, these ratios are greatly influenced by the vehicle travelling speed. When the bridge deck condition is in very good or good, the ratios can be approximated to 1.0. In addition, with the deterioration of the deck condition, the downward trend of the DLA $(M / D)$ is more obvious than that of DLA $(N / D)$. Consistent with the above conclusions, when the bridge deck condition is very poor, these two ratios may range from 0.3 to 0.5 .

4.5. DLA of the Suspender. Suspenders are the main components combined from the arch rib to the main girder. The stress characteristic of the suspender is the axial force.

4.5.1. DLA Influenced by the Pavement Roughness and Travelling Speeds. The shortest suspender and the longest suspender are selected in this paper. The other parameters are consistent with the above analysis. The results are demonstrated in Figure 16.
In Figure 16, the pavement roughness has a great impact on the DLA. The roughness increases significantly as the pavement condition worsens. Additionally, the DLA almost increases with increasing vehicle travelling speed.

4.5.2. DLAs of the Different Suspenders. As the DLA almost increases with increasing vehicle travelling speed, two travelling speeds, $5 \mathrm{~m} / \mathrm{s}$ and $40 \mathrm{~m} / \mathrm{s}$, are selected. The results of the DLAs in the different suspenders are shown in Figure 17.

When the deck condition is not worse than the average, the DLA of each suspender exhibits little difference. When the rough condition of the deck is poor or very poor, the DLA of the shortest suspender is different from that of other suspenders, and the DLA of the shortest suspender is obviously greater than other suspenders with increasing vehicle travelling speed.

The dynamic response of the shortest suspender is more obvious with the deterioration of the deck condition and increasing vehicle travelling speed, which may be one of the most important reasons why the shortest suspender of all arch bridges can be easily damaged. 


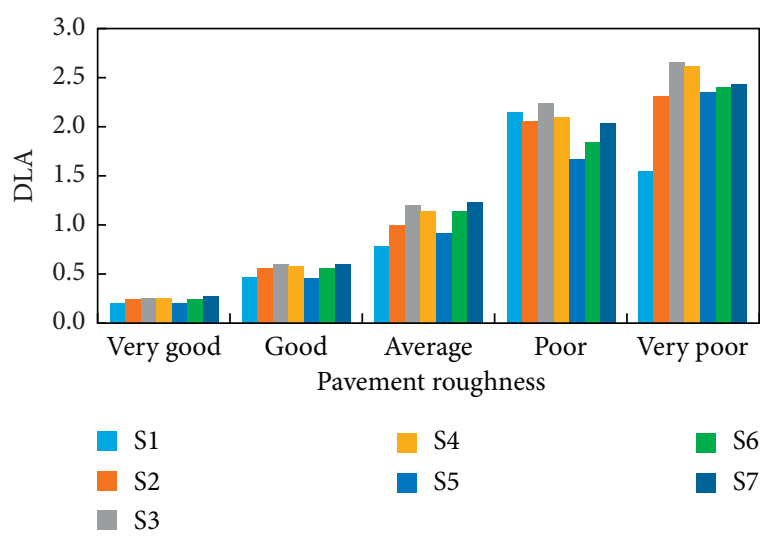

(a)

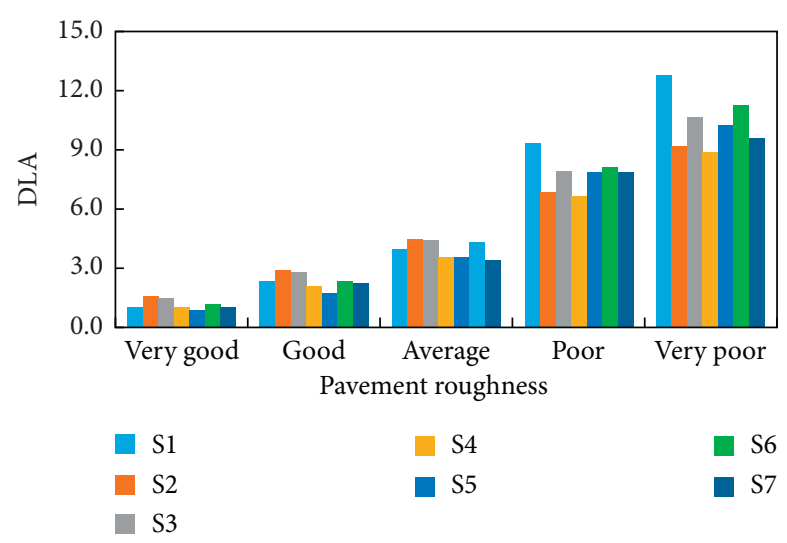

(b)

FIgURE 17: DLAs of the different suspenders: (a) $v=5 \mathrm{~m} / \mathrm{s}$; (b) $v=40 \mathrm{~m} / \mathrm{s}$.

\section{Conclusions}

Several conclusions can be drawn based on the investigations of this study, which are described as follows:

(i) The DLA of the arch rib is greater than that of the main girder under very poor deck conditions, which is contrary to the conclusion when the deck is in good condition. If the deck condition is poor in old bridges, the DLA of the arch rib must be tested, which will be much larger. For the main girders and arch ribs, the DLA $(M / D)$ and the DLA $(N / D)$ decrease as the deck condition worsens and are little influenced by the pavement roughness. When the bridge deck condition is very good or good, the ratios can be approximated to 1.0. When the bridge deck condition is very poor, these two ratios may range from 0.3 to 0.5 .

(ii) The dynamic responses of the main girders and arch ribs are quite sensitive to the vehicle locations, especially their maximum values. In contrast, the dynamic responses of the suspenders are not evidently changed. However, the cycle number of suspenders is more obvious than that of the main girders and arch ribs.

(iii) The pavement roughness has a great impact on the DLAs of the displacement, bending moment, and axial force. All of these characteristics increase significantly as the pavement condition worsens; however, these responses do not necessarily show an increasing trend with the increase in travelling speed of vehicles.

(iv) For the main girders, both the DLA $(D)$ and DLA $(M)$ in different locations vary greatly. However, the differences in DLAs among these locations are little influenced by the pavement roughness. The DLAs in different locations can vary by nearly a factor of two in most cases. For the arch ribs, when the deck condition is very poor, the change in the DLA $(M)$ with speed is more like that of the DLA $(N)$ but different from that of the DLA $(D)$. (v) For the suspenders, the DLA almost increases with increasing vehicle travelling speed. The dynamic response of the shortest suspender is more obvious with the deterioration of the deck condition and an increase in the vehicle travelling speed, which may be one of the most important reasons why the shortest suspender of all arch bridges can be easily damaged.

\section{Data Availability}

The data used to support the findings of this study are included within the article.

\section{Conflicts of Interest}

The authors declare no conflicts of interest.

\section{Authors' Contributions}

The first author was the main contributor to this work. The other authors have contributed equally to this work.

\section{Acknowledgments}

This research was financially supported by the National Natural Science Foundation of China (Grant no. 51778194), the China Postdoctoral Science Foundation (Grant no. 2017M621282), and the Fundamental Research Funds for the Central Universities (Grant no. HIT. NSRIF. 2019056).

\section{References}

[1] J. Zheng and J. Wang, "Concrete-filled steel tube arch bridges in China," Engineering, vol. 4, no. 1, pp. 143-155, 2018.

[2] D. Huang, "Dynamic and impact behavior of half-through arch bridges," Journal of Bridge Engineering, vol. 10, no. 2, pp. 133-141, 2005.

[3] C. Sun, Q. X. Wu, and B. C. Chen, "Analysis on dynamic behavior of concrete filled steel tubular arch bridge under vehicle moving loads," Journal of Highway and Transportation Research and Development, vol. 18, no. 6, pp. 543-559, 2007. 
[4] M. Yoshimura, Q. X. Wu, K. S. N. Takahashi, and K. Furukawa, "Vibration analysis of the second Saikai Bridgea concrete filled tubular (CFT) arch bridge," Journal of Sound and Vibration, vol. 290, no. 1-2, pp. 388-409, 2006.

[5] H. Wang, M. Silvast, V. Markine, and B. Wiljanen, "Analysis of the dynamic wheel loads in railway transition zones considering the moisture condition of the ballast and subballast," Applied Sciences, vol. 7, no. 12, p. 1208, 2017.

[6] Y. Li, C. S. Cai, Y. Liu, Y. Chen, and J. Liu, "Dynamic analysis of a large span specially shaped hybrid girder bridge with concrete-filled steel tube arches," Engineering Structures, vol. 106, pp. 243-260, 2016.

[7] H. Gou, W. Zhou, C. Yang, Y. Bao, and Q. Pu, "Dynamic response of a long-span concrete-filled steel tube tied arch bridge and the riding comfort of monorail trains," Applied Sciences, vol. 8, no. 4, 2018.

[8] Q. Gao, Z. Dong, K. Cui, C. Liu, and Y. Liu, "Fatigue performance of profiled steel sheeting-concrete bridge decks subjected to vehicular loads," Engineering Structures, vol. 213, Article ID 110558, 2020.

[9] X. He, K. Yu, C. Cai, Y. Zou, and X. Zhu, "Dynamic responses of a metro train-bridge system under train-braking: field measurements and data analysis," Sensors, vol. 20, no. 3, p. 735, 2020.

[10] X. Shi, C. S. Cai, and S. Chen, "Vehicle induced dynamic behavior of short-span slab bridges considering effect of approach slab condition," Journal of Bridge Engineering, vol. 13, no. 1, pp. 83-92, 2008.

[11] H. Moghimi and H. R. Ronagh, "Impact factors for a composite steel bridge using non-linear dynamic simulation," International Journal of Impact Engineering, vol. 35, no. 11, pp. 1228-1243, 2008.

[12] S. P. Brady, E. J. O’Brien, and A. Žnidarič, "Effect of vehicle velocity on the dynamic amplification of a vehicle crossing a simply supported bridge," Journal of Bridge Engineering, vol. 11, no. 2, pp. 241-249, 2006.

[13] Y. Yang, Y. Zhu, L. Wang, B. Jia, and R. Jin, "Structural damage identification of bridges from passing test vehicles," Sensors, vol. 18, no. 11, p. 4035, 2018.

[14] P. Paultre, O. Chaallal, and J. Proulx, "Bridge dynamics and dynamic amplification factors - a review of analytical and experimental findings," Canadian Journal of Civil Engineering, vol. 19, no. 2, pp. 260-278, 1992.

[15] D. L. McLean and M. L. Marsh, "Dynamic impact factors for bridges," NCHRP Synthesis, Vol. 266, Transportation Research Board, Washington, DC, USA, 1998.

[16] L. Deng, Y. Yu, Q. L. Zou, and C. S. Cai, "State-of-the-art review of dynamic impact factors of highway bridges," Journal of Bridge Engineering, vol. 20, no. 5, 2015.

[17] Q. Gao, Z. Wang, C. G. Koh, and C. Chen, "Dynamic load allowances corresponding to different responses in various sections of highway bridges to moving vehicular loads," Advances in Structural Engineering, vol. 18, no. 10, pp. 1685-1701, 2015.

[18] P. Dawe, Research Perspectives: Traffic Loading on Highway Bridges, Thomas Telford, London, UK, 2003.

[19] W. Wang, W. C. Yan, L. Deng, and H. J. Kang, "Dynamic analysis of a cable-stayed concrete-filled steel tube arch bridge under vehicle loading," Journal of Bridge Engineering, vol. 20, no. 5, 2015.

[20] S. Zhang and Y. Liu, "Damage detection of bridges monitored within one cluster based on the residual between the $\mathrm{cu}$ mulative distribution functions of strain monitoring data," Structural Health Monitoring, 2020.
[21] Z. Zhang, X. Liu, Y. Zhang, M. Zhou, and J. Chen, "Time interval of multiple crossings of the Wiener process and a fixed threshold in engineering," Mechanical Systems and Signal Processing, vol. 135, Article ID 106389, 2020.

[22] Z. L. Wang and C. H. Wang, "Dynamic performance improvement for steel-tube confined concrete arch bridge," Journal of Highway and Transportation Research and Development, vol. 23, no. 11, pp. 73-77, 2006.

[23] Q. F. Gao, K. M. Cui, J. Li, B. Q. Guo, and Y. Liu, "Optimal layout of sensors in large-span cable-stayed bridges subjected to moving vehicular loads," International Journal of Distributed Sensor Networks, vol. 16, no. 1, 2020.

[24] E. S. Hwang and A. S. Nowak, "Simulation of dynamic load for bridges," Journal of Structural Engineering, vol. 117, no. 5, pp. 1413-1434, 1991.

[25] C. Liu, D. Huang, and T.-L. Wang, "Analytical dynamic impact study based on correlated road roughness," Computers \& Structures, vol. 80, no. 20-21, pp. 1639-1650, 2002.

[26] L. Deng and C. S. Cai, "Development of dynamic impact factor for performance evaluation of existing multi-girder concrete bridges," Engineering Structures, vol. 32, no. 1, pp. 21-31, 2010.

[27] Q. F. Gao, Z. L. Wang, B. Q. Guo, and C. Chen, "Dynamic responses of simply supported girder bridges to moving vehicular loads based on mathematical method," Mathematical Problems in Engineering, vol. 2014, Article ID 514872, 2014. 